\title{
Metabolomic and proteomic analyses of a quiescent Escherichia coli cell factory reveal the mechanisms behind its production efficiency
}

Nicholas M. Thomson ${ }^{1,6^{*}}$, Tomokazu Shirai ${ }^{2}$, Marco Chiapello ${ }^{3}$, Akihiko Kondo ${ }^{2}$, Krishna J. Mukherjee $^{4}$, Easan Sivaniah ${ }^{5}$, David K. Summers ${ }^{6}$ and Keiji Numata ${ }^{1 *}$

${ }^{1}$ Enzyme Research Team, RIKEN Biomass Engineering Program, 2-1 Hirosawa, Wako-shi, Saitama, 351-0198, Japan

${ }^{2}$ Cell Factory Research Team, RIKEN Biomass Engineering Program, 1-7-22 Suehiro-cho, Tsurumiku, Yokohama, Kanagawa, 230-0045, Japan

${ }^{3}$ Cambridge Centre for Proteomics, Department of Biochemistry, University of Cambridge, Tennis Court Road, Cambridge, CB2 1QR, UK

${ }^{4}$ School of Biotechnology, Jawaharlal Nehru University, New Delhi-110067, India

${ }^{5}$ Institute for Integrated Cell-Material Sciences (iCeMS), Kyoto University, Kyoto 606-8501, Japan

${ }^{6}$ Department of Genetics, University of Cambridge, Downing Street, Cambridge, CB2 3EH, UK

${ }^{*}$ Corresponding authors.

Email: nthomson@cantab.net

Phone: +44(0)1223333985

Email: keiji.numata@ riken.jp

Phone: $+81(0) 484679525$ 


\section{$1 \quad 1$ Abstract}

2 Quiescent (Q-Cell) Escherichia coli cultures can be created by using the signalling

3 molecule indole to halt cell division of an hns mutant strain. This uncouples metabolism

4 from cell growth and allows for more efficient use of carbon feedstocks. However, the

5 reason for the increased productivity of cells in this state was previously unknown. We

6 show here that Q-cells can maintain metabolic activity in the absence of growth for up to

$7 \quad 24 \mathrm{~h}$, leading to four times greater per-cell productivity of a model metabolite, 3 -

8 hydroxybutyrate (3HB), than a control. Metabolomic data show that by disrupting the

9 proton-motive force, indole interrupts the tricarboxylic acid cycle, leading to the

10 accumulation of metabolites in the glycolysis pathway that are excellent starting points

11 for high-value chemical production. By comparing protein expression patterns between

12 wild-type and Q-cell cultures we show that Q-cells overexpress stress response proteins,

13 which prime them to tolerate the metabolic imbalances incurred through indole

14 addition. Quiescent cultures produced half the cell biomass of control cultures lacking

15 indole, but were still able to produce 39.4 g.L $\mathrm{L}^{-1}$ of $3 \mathrm{HB}$ compared to $18.6 \mathrm{~g} . \mathrm{L}^{-1}$ in the

16 control. Therefore, $Q$-cells have high potential as a platform technology for the efficient

17 production of a wide range of commodity and high value chemicals.

19 Keywords: Cell factory; Biorefining; Indole; 3-hydroxybutyric acid; Quiescence;

\section{Introduction}

22 In E. coli, carbon flux through the central carbon metabolism pathways of glycolysis, the

23 pentose phosphate pathway (PPP) and the tricarboxylic acid cycle (TCA) is at a maximum 
24 during exponential growth (Meier et al., 2011). This offers abundant opportunities for re-

25 routing of metabolic pathways for the commercial scale production of high value or

26 commodity chemicals from cheap, renewable feedstocks (Chen et al., 2013; Li, 2011;

27 Murphy, 2012; Yu et al., 2011). Consequently, E. coli-based bioproduction processes usually

28 aim to extend the exponential phase for as long as possible before nutrient limitation, oxygen

29 deprivation or the accumulation of toxic by-products inhibit further carbon metabolism and

30 cell growth (Choi et al., 2006; Lee, 1996; Singh et al., 2012). The consequential accumulation

31 of biomass (essentially a waste product) requires the diversion of feedstock for maintenance

32 of cell function and production of essential macromolecules (Van Bodegom, 2007).

34 Alternatives to high cell density growth are used in certain circumstances, including

35 continuous production using a chemostat (Hoskisson and Hobbs, 2005; Hua et al., 2004) and

36 the use of 'resting cells' in an osmotically-balanced but nutrient-limited buffer such as

37 phosphate buffered saline (Cha et al., 1999; Ghazi et al., 1983). However, these approaches

38 are technically more challenging and suffer from problems including vulnerability to

39 contamination in chemostats and limited viable lifespans of resting cells.

41 Quiescence is achieved by addition of $2.5-3.0 \mathrm{mM}$ indole to cultures of E. coli $\mathrm{W} 3110$

42 carrying a stop codon after the $93^{\text {rd }}$ codon of the $h n s$ gene ( $\left.h n s \Delta 93\right)$. This mutation causes the 43 production of a truncated Histone-like Nucleoid Structuring protein (H-NS). After indole is

44 added, metabolic activity continues and production of plasmid-encoded proteins is increased,

45 but only in hns mutants (Chen et al., 2015; Mukherjee et al., 2004; Rowe and Summers,

46 1999). Indole is a well-studied chemical signal in over 85 species of bacteria (Lee and Lee,

47 2010). It is a proton ionophore and has been shown to reduce the proton-motive force (PMF)

48 of $E$. coli by allowing protons to return to the cytoplasm after their expulsion to the 
49 periplasmic space during oxidative phosphorylation (Chimerel et al., 2013). One effect of

50 reducing the PMF is to prevent the formation of the FtsZ ring, which is a prerequisite for cell

51 division. Therefore, at suitable concentrations indole is able to prevent $E$. coli cell division

52 (Chimerel et al., 2012).

53

54 Here, we investigated the changes in central carbon metabolism and protein expression that

55 are induced by indole addition in wild-type and Q-cell (hns $\Delta 93)$ cultures under fed-batch

56 conditions. Taking into account the results of these experiments, we designed a simple

57 fermentation strategy for improved production of $3 \mathrm{HB}$.

\section{Results}

59 We conducted a time-course study by growing the wild-type or $h n s \Delta 93$ mutant strain of $E$.

60 coli $\mathrm{W} 3110$ in $3 \mathrm{~L}$ aerobic, fed-batch fermentations with or without the addition of indole.

61 The hns $\Delta 93$ cultures grew slower than the wild-type (Fig. 1a). Therefore, we normalized the

62 early culture conditions by inoculating into modified mineral salts medium (M9GYT)

63 containing $0.4 \%$ glucose and growing until the initial carbon supply was exhausted. At this

64 stage, every culture reached the same optical density at $600 \mathrm{~nm}\left(\mathrm{OD}_{600}\right.$; overall average 6.69 ,

65 standard deviation 0.48). The nutrient feed was then started and the time-course was begun 30

66 min later by addition of indole (final concentration of $3 \mathrm{mM}$ from a $1 \mathrm{M}$ stock dissolved in

67 ethanol) or an equivalent volume of pure ethanol. Only hns $\Delta 93$ cultures entered quiescence,

68 whereas wild-type growth was inhibited but not stopped by indole.

69

70 We analyzed 22 cofactors and intermediates of glycolysis and PPP using liquid

71 chromatography - tandem mass spectrometry (LC-MS/MS) and 8 organic acids (pyruvate,

72 lactate and intermediates of TCA) by gas chromatography - mass spectrometry (GC-MS). 
73 Glucose-ADP, isocitrate and NADH were removed from the analysis due to very low

74 abundances. The quantitative (GC-MS and HPLC) and relative ratio (LC-MS/MS)

75 concentrations for the remaining 27 species were normalized against the $\mathrm{OD}_{600}$ of the cultures

76 at each time point. Results using each technology were then analyzed in parallel, since direct

77 comparisons between the two concentration reporting modes were not possible.

\section{$78 \quad 3.1$ The metabolic effects of indole are strongest during exponential growth}

79 Metabolites tended to cluster with neighboring intermediates of their respective pathways

80 (Fig. 1b,d), showing that any metabolic changes tended to affect whole pathways more than

81 individual intermediates. Individual principal component analyses (PCA) for each time-point

82 of the LC-MS/MS data revealed a dynamic interaction between the influences of strain

83 differences and indole (Fig. 2, Supplementary Fig. 1). Before indole addition, the samples

84 were relatively closely clustered with some separation by strain along principal component

85 (PC) 1 (accounting for $56 \%$ of the observed difference). Within 5 min of indole addition,

86 indole treatment became the dominant clustering factor, while PC1 became less important

87 (38.3\% of observed differences). The influence of indole became more pronounced over the

88 following $60 \mathrm{~min}$, but by $240 \mathrm{~min}$ the samples tended to cluster more closely again, with

89 some separation by strain. Untreated culture density was already high by this time and growth

90 may have begun to slow. This suggests that the quiescent metabolic state resembles the late-

91 logarithmic or early stationary phase of batch cultures. The GC-MS data revealed a similar

92 trend for organic acids (Supplementary Fig. 2). 


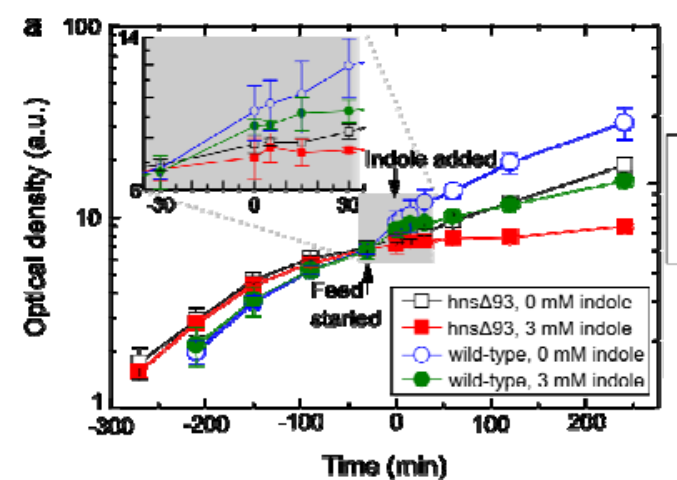

c

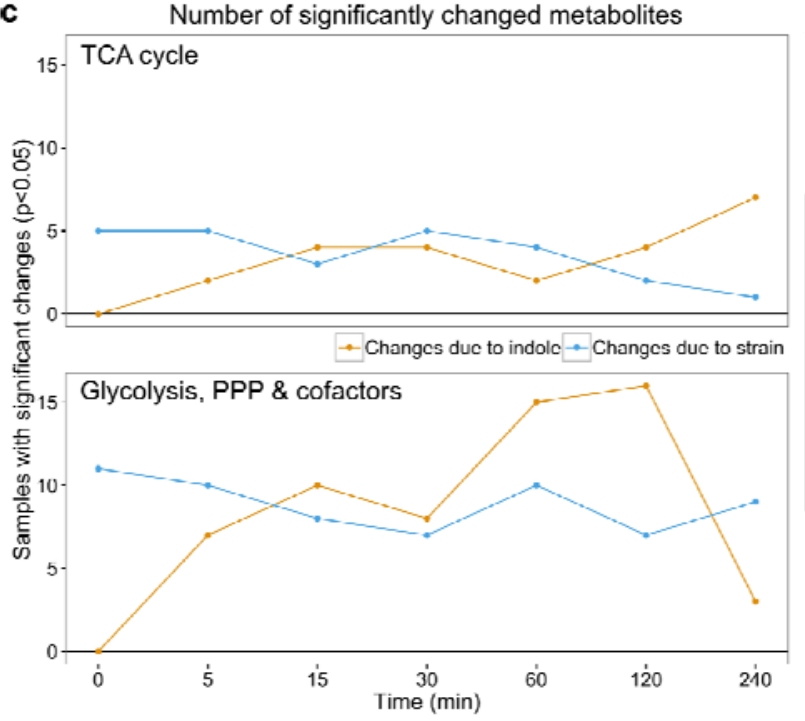

b GC-MS (TCA cycle)

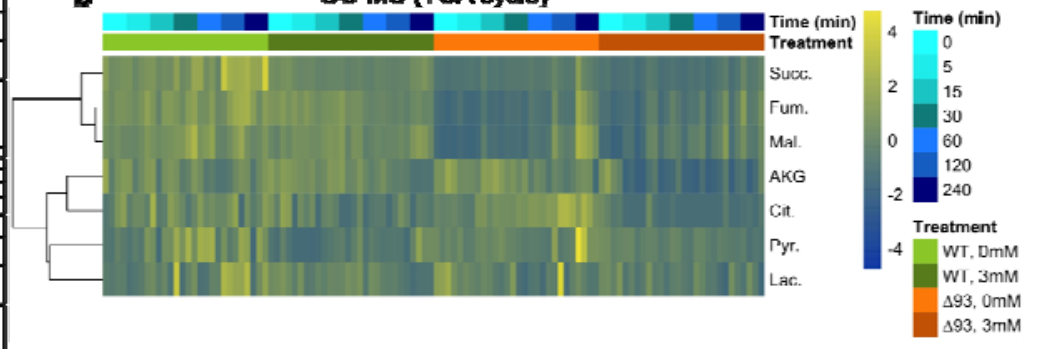

d LC-MSMS (Giycolysis, PPP a cofactors)

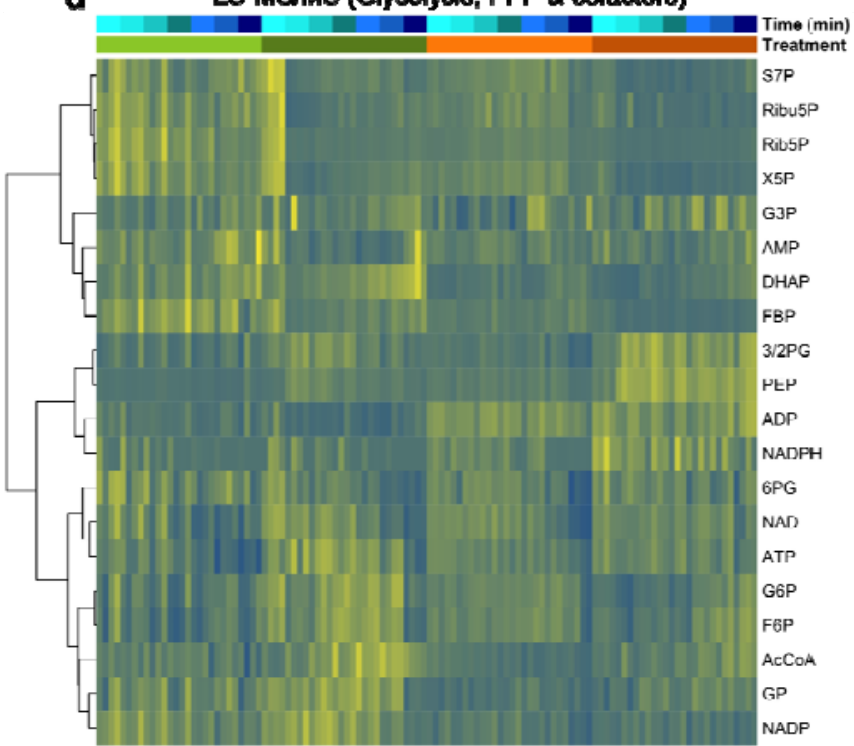

93

94

95

96

97

98

99

100

101

102

103

104

105

106

107

108
Figure. 1: Growth and changes in metabolite concentration. a, Growth curves of each strain during the timecourse experiment. The inset graph shows a magnified area of the same data from the time feeding was started until 30 mins into the time-course. Error bars represent the standard deviations $(n=4)$. b, Heat map of concentration changes in intermediates of the TCA cycle plus pyruvate and lactate, analyzed by GC-MS. c, Summary of the individual ANOVA analyses for each time-point showing the increasing importance of indoleinduced concentration changes over time. $\mathbf{d}$, Heat map of concentration changes in cofactors and intermediates of glycolysis and PPP analyzed by LC-MS/MS. Abbreviations for metabolite names: S7P, sedoheptulose-7phosphate; Ribu5P, ribulose-5-phosphate; Rib5P, ribose-5-phosphate; X5P, xylulose-5-phosphate; G3P, glyceraldehyde-3-phosphate; AMP, adenosine monophosphate; DHAP, dihydrox yacetone phosphate; FBP, fructose-1,6-bisphosphate; 3/2PG, 3-phosphoglycerate \& 2-phosphoglycerate; PEP, phosphoenolpyruvate; ADP, adenosine diphosphate; 6PG, 6-phosphogluconate; ATP, adenosine triphosphate; G6P, glucose-6-phosphate; F6P, fructose-6-phosphate; AcCoA, acetyl-Coenzyme A; GP, glucose-1-phosphate; NAD, oxidized nicotinamide adenine dinucleotide (NAD); NADH, reduced (NAD); NADP, oxidized NAD phosphate (NADP); NADPH, reduced NADP; Succ., succinate; Fum., fumarate; Mal., malate; AKG, $\alpha$-ketoglutarate; Cit., citrate; Pyr., pyruvate; Lac., lactate. 
110 We also observed the temporally changing influence of indole by conducting individual

111 ANOVA tests for each time-point (Fig. 1c). The number of metabolites with a significant

112 change due to strain remained fairly constant throughout the time-course, whereas indole-

113 associated changes increased over $120 \mathrm{~min}$ before falling again by $240 \mathrm{~min}$.
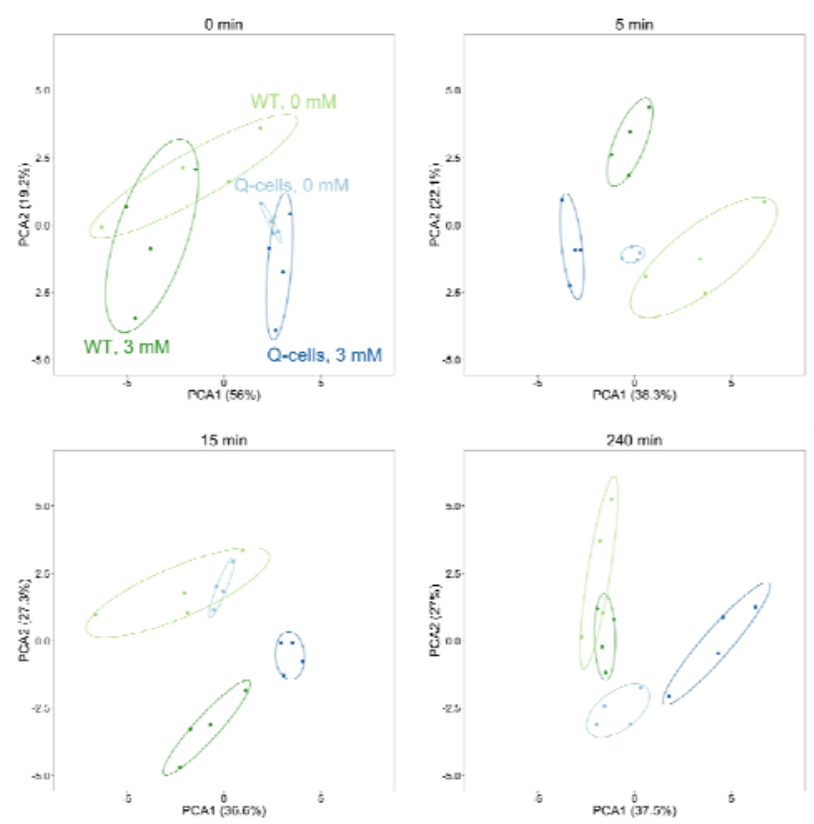

114 Figure 2: Individual principal component analyses of four time points for the metabolites analyzed by LC-

115 MS/MS. These time-points were chosen to demonstrate the rapid (<5 min) but reversible (<240 min) response

116 to indole addition, which outweighed the differences between the wild-type and hns $\Delta 93$ strains. Points represent individual fermentations $(\mathrm{n}=4)$ and ellipses represent $95 \%$ confidence intervals. The full series of PCA analyses for LC-MS/MS and GC-MS data are shown in Supplementary Fig. 1 and 2.

\subsection{Indole provides an increased pool of available metabolites from glycolysis in hns 493}

cells

To identify the metabolites with the most significant changes in concentration during

quiescence, we compared the time-courses of each metabolite between the control (wild-type,

$0 \mathrm{mM}$ indole) and quiescent cultures, and ranked each metabolite by the variation in time-

125 (Tai and Speed, 2006). The individual graphs of concentration versus time for each metabolite 
127 or reduced in concentration over time under either condition (Table 1). However, glycolysis

128 intermediates were present at higher concentrations in quiescent cells than in the control. We

129 noted particularly significant increases in phosphoenolpyruvate (PEP), 3-phosphoglycerate

130 and 2-PG (3/2-PG), and acetyl-Coenzyme A (Ac-CoA), of which the latter two increased over

131 time in quiescent cells but decreased in the control.

132 Table 1: Most significantly changed metabolites during the time-course experiment

\begin{tabular}{lcccc}
\hline Metabolite & Pathway & $\begin{array}{c}\text { Fold change } \\
\text { in WT, 0 mM }\end{array}$ & $\begin{array}{c}\text { Fold change } \\
\text { in hns } \mathbf{~ 9 3 , 3 ~ m M ~}\end{array}$ & Hotelling T $^{\mathbf{2}}$ \\
\hline LC-MS/MS & & & & \\
Phosphoenolpyruvate & Glycolysis & 1.13 & 2.91 & 87.62 \\
Sedoheptulose-7-P & PPP & -1.03 & -1.23 & 58.72 \\
NAD & Cofactor & -1.48 & -1.28 & 53.53 \\
Fructose-1,6-BP & Glycolysis & -1.65 & -1.30 & 50.44 \\
3/2-phosphoglycerate & Glycolysis & -1.01 & 1.53 & 48.97 \\
ADP & Cofactor & -1.28 & 1.09 & 48.66 \\
Acetyl-CoA & Glycolysis/TCA & -1.27 & 1.41 & 42.27 \\
& & & & \\
Ribose-5-P & PPP & -2.56 & -1.38 & 35.69 \\
Xylulose-5-P & PPP & -1.76 & -1.70 & 34.58 \\
Ribulose-5-P & PPP & -1.35 & -1.76 & 33.05 \\
& & & & \\
GC-MS & & & & \\
$\alpha$-ketoglutarate & TCA & -1.13 & -1.52 & 95.42 \\
Malate & TCA & 1.03 & 2.00 & 73.18 \\
Succinate & TCA & 1.72 & 2.06 & 72.79 \\
Fumarate & TCA & 1.16 & 1.74 & 70.56 \\
Citrate & TCA & 1.23 & -2.81 & 64.18 \\
Pyruvate & Glycolysis/TCA & 1.64 & -1.63 & 49.01 \\
Lactate & Other & 1.57 & -1.51 & 42.51 \\
\hline
\end{tabular}

133

134 Both strains had identical flux ratios through glycolysis, PPP and the Entner-Doudoroff

135 pathway in ${ }^{13} \mathrm{C}$-labelled chemostat experiments without indole (Supplementary Table 1). Due

136 to its effect on growth, we could not investigate the changes in metabolic flux caused by

137 indole. However Fig. 1b,d and Table 1 both suggest that indole causes a non-H-NS dependent

138 re-routing of metabolic flux away from the PPP, which results in a build-up of intermediates

139 in the glycolysis pathway. 
141 MEBA also revealed an effect of quiescence on the TCA cycle (Table 1). In control cultures,

142 TCA intermediates slowly increase in concentration during growth. However, in quiescent

143 cultures pyruvate and acids from the first half of TCA reduced in concentration, whereas

144 those in the second half increased above the levels of the control. With the simultaneous

145 increase in Ac-CoA, this suggests indole inhibits the TCA cycle, possibly by preventing the

146 conversion of Ac-CoA to citrate.

147

148 An alternative explanation could be that the glyoxylate cycle is stimulated in the presence of

149 indole (Fig. 3). The glyoxylate cycle is an anabolic pathway that allows growth on simple

150 carbon sources such as acetate in the absence of glucose, relying on isocitrate lyase (AceA)

151 and two isozymes of malate synthase (AceB and GlcB) (Cronan, Jr. and Laporte, 2006;

152 Maharjan et al., 2005). HPLC analysis of culture supernatants showed that acetate was the

153 only organic acid secreted by the cells, and was produced at approximately $30 \%$ higher

154 specific concentration by $h n s \Delta 93$ than by wild-type cells. Since acetate stimulates the

155 glyoxylate cycle (Maloy and Nunn, 1982; Ornston and Ornston, 1969) it is plausible that

156 higher concentrations of acetate might result in a higher flux through the glyoxylate cycle

157 even when glucose is present. Using quantitative real-time PCR (qRT-PCR) we measured

$158 a c e B$ and $g l c B$ expression levels 1.6-fold $(\mathrm{p}<0.01)$ and 1.2-fold $(\mathrm{p}<0.05)$ higher in $h n s \Delta 93$

159 than wild-type, respectively. In addition aceA had 1.4-fold higher expression ( $\mathrm{p}=0.07)$.

160 These results lend some support to the hypothesis that the glyoxylate cycle is more active in

161 the $h n s \Delta 93$ mutant, although further work would be necessary to confirm whether the modest

162 increases in gene expression have a significant effect on metabolic activity. 


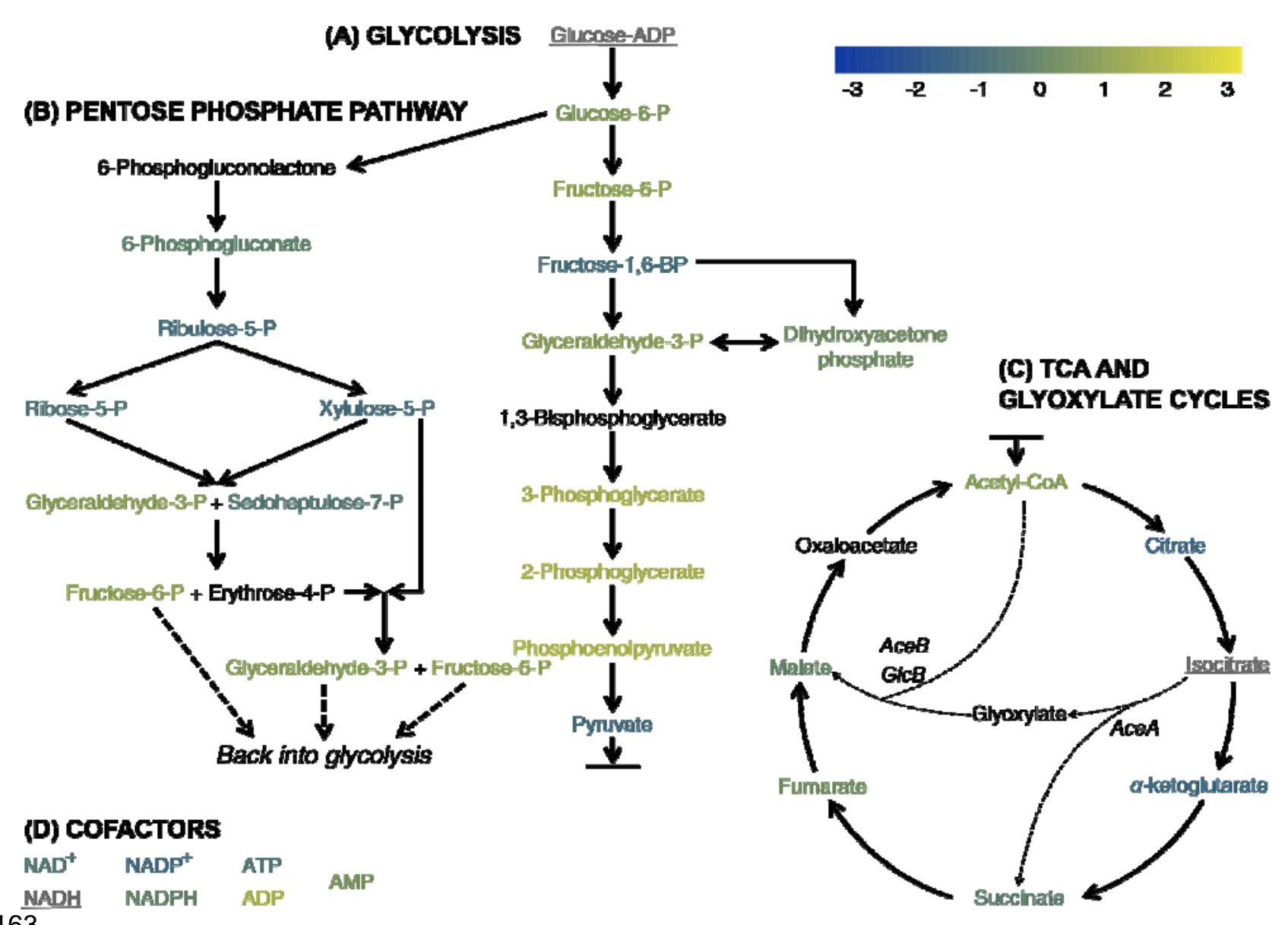

Figure 3: Overview of changes in central carbon metabolism in quiescent E. coli at 240 min. The color of each metabolite name corresponds to the average mean-centered fold change in concentration $(n=4)$ at the end of the time-course experiment for quiescent cultures (hns $\Delta 93$ with $3 \mathrm{mM}$ indole). Metabolites in grey, underlined text had concentrations below the limit of detection. Those in black text were not possible to detect with our system. Italic font indicates the names of enzymes involved in the glyoxylate pathway.

169

170 A key function of the TCA cycle is to reduce NAD ${ }^{+}$to NADH, which acts as an electron

171 donor for the electron transport chain. In our experiment, the concentration of $\mathrm{NAD}^{+}$and the

172 related molecule $\mathrm{NADP}^{+}$slowly decreased over $4 \mathrm{~h}$ under all conditions, but remained highest

173 for $h n s \Delta 93$ with $3 \mathrm{mM}$ indole (Supplementary Fig. 6). The concentrations of the reduced

174 forms of both molecules were also lower than the oxidized forms; in the case of NADH,

175 below the limit of detection. Furthermore, adenosine phosphate concentrations remained more

176 constant in quiescent cultures than under other conditions. Therefore, the quiescent state must

177 involve a homeostatic mechanism by which cofactor concentrations are controlled. 


\subsection{Global protein expression changes are primarily due to the hns mutation}

179 Since H-NS regulates approximately $5 \%$ of all gene expression in E. coli (Hommais et al.,

180 2001) we speculated that the $h n s \Delta 93$ mutation might affect the expression of proteins

181 involved in metabolism and stress response. Therefore, we drew samples for protein expression profiling in parallel with samples for metabolite analysis $1 \mathrm{~h}$ into the time-course

all the variation in protein expression was due to the strain genotype rather than indole addition (Fig. 4a,b). A total of 424 protein spots were present in every spot map (complete cases), with $32 \%$ of those differing significantly $(\mathrm{p} \leq 0.05)$ due to the strain (Fig. $4 c)$. Using more stringent criteria, we identified 43 protein spots with $\geq 3$-fold increase or decrease in expression compared to the control ( $\mathrm{p} \leq 0.001)$. ANOVA for the 43 selected spots showed that 39 spots varied due to the strain and 2 spots due to indole addition. The remaining 2 spots varied due to a combination of indole and strain, although there was no interaction.

The 43 selected spots were excised from the gel, digested by trypsin and subjected to peptide fingerprinting analysis via mass spectrometry. The results were queried against the SwissProt database using MASCOT v.2.4.1, and we were able to identify 12 spots with a high certainty of representing a single protein (or, in one case, two) (Table 2). Of the 12 proteins identified,

197 functions and were up-regulated in the $h n s \Delta 93$ strain. This suggests Q-cells might be 'primed'

198 for metabolic stresses induced by indole addition to the medium. Interestingly, PyrB

199 expression was also reduced in $h n s \Delta 93$. We noted earlier that the $h n s \Delta 93$ mutant grew more

200 slowly than the wild-type in mineral salts medium. PyrB knockout mutants are unable to grow in M9 medium due to a reduction in nucleotide synthesis, so the reduction in PyrB expression 
bioRxiv preprint doi: https://doi.org/10.1101/082305; this version posted October 20, 2016. The copyright holder for this preprint (which was not certified by peer review) is the author/funder. All rights reserved. No reuse allowed without permission.

.

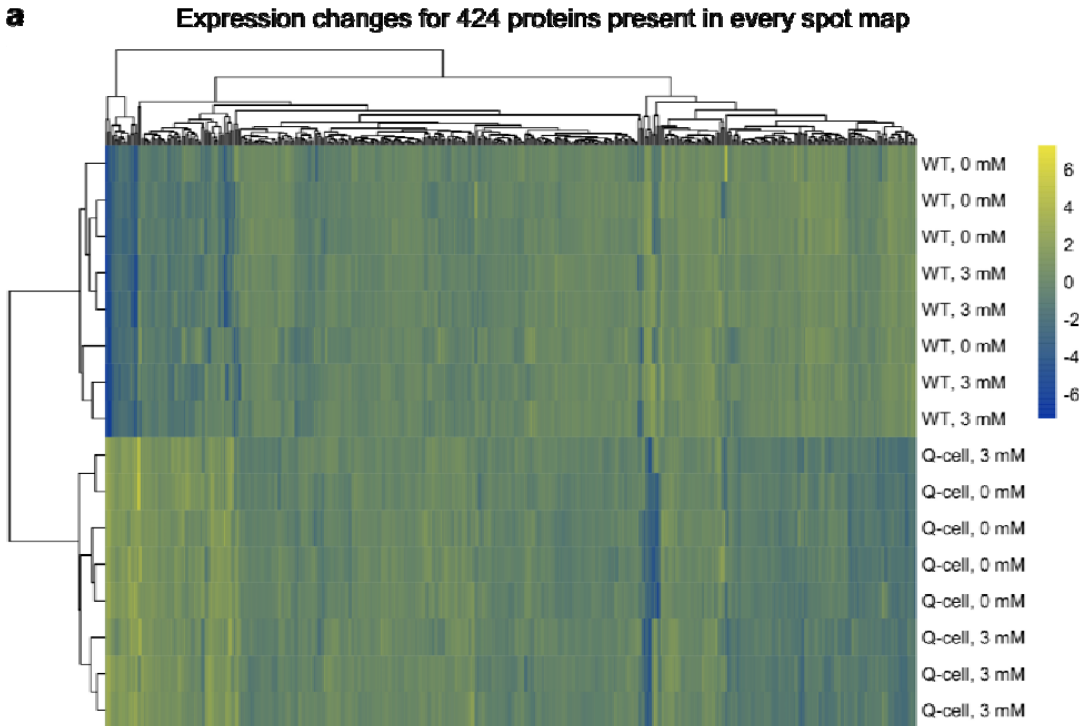

b
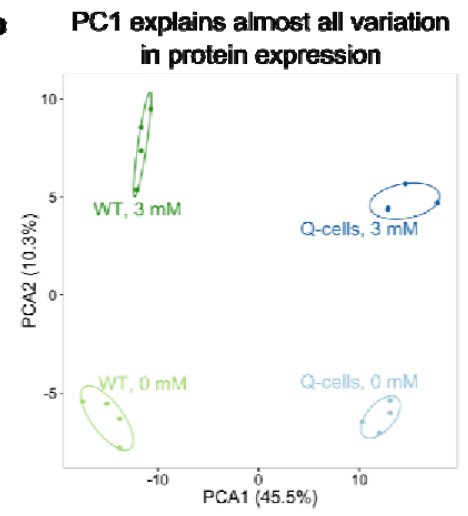

c Factors associated with expression changes

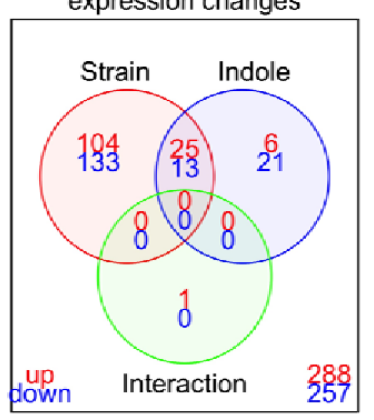

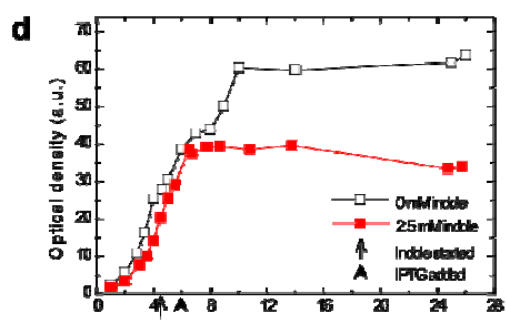

e

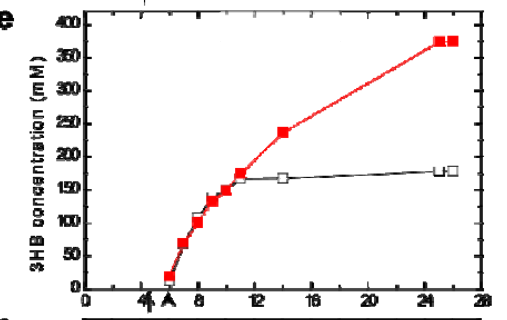

f

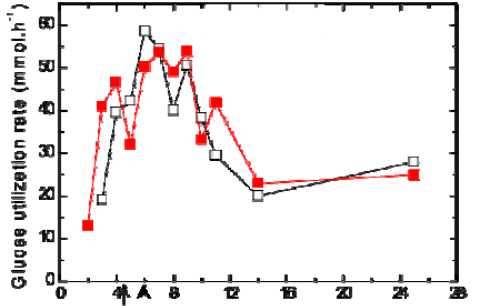

g

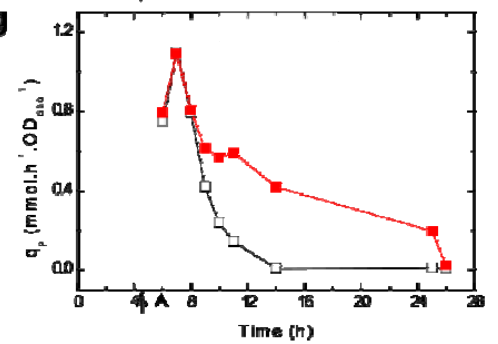

Figure 4: Global changes in protein expression, and increased production of $3 \mathrm{HB}$ in quiescent cultures. a, Heat map of fold-changes in protein expression determined by 2d-DIGE for 424 complete cases. b. Principal component analysis on the protein expression data confirms a single principal component accounted for the majority of variation, with separation primarily by strain. c, Significantly up- and down-regulated proteins from the complete cases, grouped by the cause(s) of the change in expression, as determined by ANOVA (adj. $\mathrm{p}<$ $0.05)$. d - g, Fed-batch cultures of E. coli W3110hns $\Delta 93$ producing $3 \mathrm{HB}$, with or without the addition of indole $(2.5 \mathrm{mM})$, showing that as cells enter quiescence their metabolic effort is diverted away from biomass production and can be harnessed for the production of $3 \mathrm{HB}$ by metabolic pathway engineering. We show here the results of the experiment in which $2.5 \mathrm{mM}$ indole was used. Similar results were achieved with other indole concentrations but are not directly comparable. d, Indole addition (arrows) caused the culture to become quiescent within $2 \mathrm{~h}$. e, Cumulative 3HB production following induction with IPTG (arrow heads). While the quiescent culture remained productive, the control stopped producing $3 \mathrm{HB}$ upon entry into stationary phase. $\mathbf{f}$, Glucose utilization rates were the same for both strains throughout the experiment. g, Specific 3HB formation rates $\left(\mathrm{q}_{\mathrm{p}}\right)$ were initially the same, but reduced in the control during stationary phase. 
Table 2: Identities and properties of proteins with greater than 3-fold change in concentration from the control $(\mathbf{p}<0.001)$

\begin{tabular}{|c|c|c|c|c|c|c|}
\hline $\begin{array}{l}\text { Spot } \\
\text { ID }\end{array}$ & Protein Name & Gene & $\begin{array}{l}\text { Theoretical } \\
\mathbf{M}_{\mathbf{r}}\end{array}$ & $\begin{array}{l}\text { Fold } \\
\text { Change }^{\square}\end{array}$ & $\begin{array}{l}\text { Change } \\
\text { due to: }\end{array}$ & Pathway / function \\
\hline 877 & $\begin{array}{l}\text { NADP-specific glutamate } \\
\text { dehydrogenase }\end{array}$ & $\operatorname{gdhA}$ & 48,778 & -4.14 & Strain & Glutamate synthesis \\
\hline 1319 & $\begin{array}{l}\text { Aspartate } \\
\text { carbamoyltransferase }\end{array}$ & pyrB & 34,463 & -6.23 & Strain & $\begin{array}{l}\text { Pyrimidine } \\
\text { nucleotide synthesis }\end{array}$ \\
\hline $1932 *$ & Protein YciF & yciF & 18,643 & 14.90 & Strain & Osmotic shock \\
\hline $1988 *$ & $\begin{array}{l}\text { Aspartate } \\
\text { carbamoyltransferase } \\
\text { regulatory chain }\end{array}$ & pyrI & 17,338 & -4.59 & Strain & $\begin{array}{l}\text { Regulatory partner } \\
\text { of PyrB }\end{array}$ \\
\hline $2090 *$ & Protein YciE & yciE & 19,007 & 14.67 & Strain & Osmotic shock \\
\hline $2050 *$ & $\begin{array}{l}\text { DNA protection during } \\
\text { starvation protein }\end{array}$ & dps & 18,684 & 5.82 & Strain & DNA protection \\
\hline $2121 *$ & $\begin{array}{l}\text { 50S ribosomal protein } \\
\text { L10 }\end{array}$ & rlpJ & 17,757 & 6.94 & Strain & $\begin{array}{l}\text { Ribosome } \\
\text { component }\end{array}$ \\
\hline $2145^{*}$ & $\begin{array}{l}\text { Uncharacterised protein } \\
\text { YgaU }\end{array}$ & ygaU & 16,053 & 3.68 & Strain & Osmotic shock \\
\hline $2153 *$ & Peroxiredoxin & osmC & 15,193 & 4.70 & Strain & Oxidative stress \\
\hline \multirow[t]{2}{*}{2235} & $\begin{array}{l}\text { 1) 50S Ribosomal protein } \\
\text { L9 }\end{array}$ & 1) rplI & 1) 12,149 & 3.40 & Indole & $\begin{array}{l}\text { 1) Ribosome } \\
\text { component }\end{array}$ \\
\hline & $\begin{array}{l}\text { 2) Outer membrane } \\
\text { assembly factor }\end{array}$ & 2) bamE & 2) 12,408 & & & 2) Unknown \\
\hline 2314 & Thioredoxin-1 & $\operatorname{trx} A$ & 11,913 & 3.25 & Strain & $\begin{array}{l}\text { Control of redox } \\
\text { potential }\end{array}$ \\
\hline $2375^{*}$ & Protein YjbJ & yjbJ & 8,320 & 8.90 & Strain & Osmotic shock \\
\hline
\end{tabular}

* Regulated by H-NS

Average fold change in expression level $(n=4) 1 \mathrm{~h}$ into the time-course experiment. Positive numbers represent increased concentration and negative numbers represent a decrease.

\subsection{Application of Q-cells to the production of 3-hydroxybutyrate}

The build-up of glycolysis intermediates, and the fact that fewer resources are diverted 3HB was chosen as a model for metabolite production as it requires the expression of only three heterologous enzymes for its production from Ac-CoA and its presence in the growth medium can be assayed simply with commercially-available kits. To produce $3 \mathrm{HB}$, two molecules of Ac-CoA are condensed by a $\beta$-ketothiolase (PhaA from Cupriavidus necator) and reduced at the $\beta$-position by an acetoacetyl-CoA reductase (PhaB from $C$. necator), 
234 biosynthetic pathway would exploit the large accumulation of PEP and Ac-CoA in quiescent 235 cultures (Fig. 1d and Table 1).

236

237 We introduced plasmid pTrctesBphaAB into E. coli $\mathrm{W} 3110 h n s \Delta 93$ to enable it to produce 3238 hydroxybutyrate $(3 \mathrm{HB})$ in an IPTG-inducible manner. Terrific broth (TB) with glucose as the 239 carbon source was chosen as the culture medium to avoid the slow growth of the $h n s \Delta 93$ 240 strain in M9GYT (Fig. 1a) (Tartof and Hobbs, 1987). Pilot experiments demonstrated that 241 quiescence could be achieved with $2.5 \mathrm{mM}$ indole so we used this concentration to minimize 242 the potential for indole toxicity. After $26 \mathrm{~h}$ the quiescent culture reached an $\mathrm{OD}_{600}$ of 34.0 , 243 compared to 63.7 for a control culture with ethanol added in place of the indole solution (Fig.

244 4d). This corresponded to dried cell weights (DCW) of 13.3 g.L. $\mathrm{L}^{-1}$ and 24.8 g.L $\mathrm{L}^{-1}$ respectively.

245 Growth of the cultures was almost identical until indole addition, after which the Q-cell

246 culture ceased growing almost immediately. Despite the reduced cell density, the 3HB

247 concentration in the Q-cell culture reached $374.8 \mathrm{mM}\left(39.4\right.$ g. $\left.\mathrm{L}^{-1}\right)$ at $26 \mathrm{~h}$ compared to 178.4

$248 \mathrm{mM}\left(18.6 \mathrm{~g} . \mathrm{L}^{-1}\right)$ for the control (Fig. 4e). Therefore, over the course of the experiment, the

249 product yield (grams of product formed per liter divided by grams of cells formed per liter) of

250 the quiescent culture was 4.0-fold greater than for the control (2.97 against 0.75 ), while the

251 absolute concentration in the culture supernatant was 2.1-fold greater.

252

253 Importantly, the rates of substrate (glucose, S) utilization (dS/dt) were very similar for both

254 cultures at all stages of the fermentation (Fig. 4f). On the other hand, the specific product

$255(3 \mathrm{HB}, \mathrm{P})$ formation rates (given by $1 / \mathrm{X}(\mathrm{dP} / \mathrm{dt})$, where $\mathrm{X}$ is biomass), representing the amount

256 of $3 \mathrm{HB}$ produced per unit of time per unit of biomass, were initially similar but diverged $9 \mathrm{~h}$

257 into the experiment (Fig. 4g). Comparison with Fig. 4d demonstrates that the divergence

258 corresponds with entry of the control culture into stationary phase. 3HB production is linked 
259 to the metabolic rate of the cell. Therefore, the control culture became unproductive as

260 metabolism slowed upon entry into stationary phase, whereas the quiescent culture continued

261 to produce $3 \mathrm{HB}$. It is this extended production period that accounts for the superior

262 productivity of quiescent cultures. Ceasing growth clearly allows quiescent cultures to take

263 advantage of the large pool of available metabolites that were revealed by our metabolomics

264 analysis.

\section{Discussion}

266 We show here that the $h n s \Delta 93$ mutation leads to wide-scale changes in protein expression.

267 These changes did not greatly affect the balance or concentration of metabolites between the

268 strains. Most significantly, stress response genes were upregulated, in agreement with

269 previous characterization of protein expression changes in an hns knockout strain (Laurent-

270 Winter et al., 1997). A detailed survey of expression changes due to indole has not been

271 carried out in E. coli, but it has been suggested that proteins involved in drug and acid

272 resistance (Hirakawa et al., 2010, 2005; Lee et al., 2010), biofilm formation (Di Martino et

273 al., 2003; Lee et al., 2007; Wood, 2009), amino acid metabolism (Wang et al., 2001),

274 virulence (Hirakawa et al., 2009), and even inter-species communication (Lee and Lee, 2010;

275 Vega et al., 2013) are all affected by indole. A microarray study of indole-induced expression

276 changes in Salmonella found 77 differentially expressed proteins (Nikaido et al., 2012).

277 Although we imposed more stringent cut-off parameters for the selection of significant

278 expression changes, our results are in agreement that indole does not affect the expression of a

279 large number of genes.

280

281 DNA replication and gene transcription in E. coli are coordinated throughout the growth cycle

282 by controlling the topological structure of the chromosome (Balke and Gralla, 1987; Hsieh et 
al., 1991; Ohniwa et al., 2006). It has also been suggested that a high density of DNA gyrase

284 binding sites (and consequently high superhelical density) near to the replication origin is

285 correlated with genes that are expressed early in the growth cycle (Lau et al., 2004; Sobetzko

286 et al., 2012). Indole inhibits DNA gyrase, but is not thought to have a strong effect at $3 \mathrm{mM}$

287 (Field and Summers, 2012). Therefore, the protein expression and metabolic effects we

288 observed are unlikely to be a consequence of DNA gyrase inhibition by indole. As noted

289 before, other mutations in hns do not allow the induction of quiescence (Rowe and Summers,

290 1999). Therefore, we conclude that the hns $\Delta 93$ mutation affects the binding of H-NS to DNA

291 in a way that loosens its control over the expression of a subset of the genes which it inhibits,

292 and that this subset includes a large number of stress response genes.

293

294 It is not necessary for indole to affect protein expression in order to influence metabolite

295 concentrations since metabolic balance is controlled largely through modulation of enzyme

296 activity (Ishii et al., 2007). As a protonophore, indole reduces the PMF, leading to increased

297 proton pumping by the electron transfer chain (Korshunov et al., 1997). This stimulates a

298 demand for NADH from the TCA cycle, leading to an increased rate of respiration. However,

299 in our experiments the TCA cycle was disrupted. Continued supply of glucose into glycolysis

300 but reduced activity in the TCA cycle led to the build-up of glycolytic intermediates,

301 particularly at the junction between glycolysis and the TCA cycle.

302

303 Our results suggest that the $h n s \Delta 93$ mutation essentially 'primes' cells for the effect of indole

304 on metabolism and prepares the cells for quiescence. When indole is present, metabolism

305 proceeds in a redox-imbalanced fashion, resulting in a reduction in $\mathrm{NAD}^{+}$and $\mathrm{NADP}^{+}$

306 concentrations as the pathways that regenerate them are inhibited (Fig. 3). In the wild-type

307 strain this soon leads to oxidative damage by reactive oxygen species (ROS) (Cabiscol et al., 
2000; Krapp et al., 2011). However, in $h n s \Delta 93$, elevated concentrations of stress-response

309 proteins may enable the ROS to be neutralized, partly by oxidizing NADH and NADPH.

310 Therefore, the increased defense against oxidative stress in Q-cells may also act to regenerate

311 cofactors, allowing for continued glucose metabolism. This model of indole action could shed

312 further light on the metabolic shift that takes place as wild-type cells transition from

313 exponential to stationary phase (Gaimster and Summers, 2015). For example, it might be of

314 benefit for cells to repress the TCA cycle when less energy is required to power cell growth

315 and division, and divert metabolic energy towards cell maintenance pathways leading from

316 the PPP and glycolysis.

317

318 As an example of the productive capacity of the Q-cell system we demonstrated enhanced

319 production of $3 \mathrm{HB}$. Other than adjusting the indole concentration, we made no attempt to

320 optimize the production conditions. However, the 39.4 g. $\mathrm{L}^{-1}$ of $3 \mathrm{HB}$ produced here was still

321 greater than the highest previously reported productivity of $3 \mathrm{HB}$ of 12.2 g.L $\mathrm{L}^{-1}$ from 16.7 g.L $\mathrm{L}^{-1}$

322 DCW (Liu et al., 2007).

323

324 By better understanding the mechanism of entry into quiescence we have been able to identify

325 promising starting points for metabolic engineering to improve the $h n s \Delta 93$ strain for the

326 production of commercially significant products through exploitation of the accumulated

327 glycolysis intermediates. The uncoupling of production from biomass generation clearly leads

328 to large increases in efficiency. Therefore, we believe that with additional metabolic

329 engineering and optimization of growth conditions, the Q-cell system will become a powerful

330 and flexible tool for industrial-scale production of a variety of high value chemicals. 
332 Strains and growth conditions. The wild-type strain used as the control was E. coli W3110 (ATCC 27325). To

333 create the Q-cell strain, the hns $\Delta 93$ mutation was introduced to the wild-type strain using the lambda Red

334 recombinase system, as described previously (Chen et al., 2015). Strains were stored with glycerol at $-80{ }^{\circ} \mathrm{C}$ and

335 streaked onto Luria-Bertani (LB) agar plates before use. A $5 \mathrm{ml}$ starter culture was then grown in LB liquid

336 medium for $8 \mathrm{~h}$ at $37^{\circ} \mathrm{C}$ and used to inoculate further cultures for the experiments. The $h n s \Delta 93$ mutation confers

337 kanamycin resistance to the Q-cell strain. For selection purposes, Q-cell plates and starter cultures contained

338 kanamycin $\left(30 \mu \mathrm{g} \cdot \mathrm{ml}^{-1}\right)$. However, to keep the conditions used for each strain as similar as possible, no

339 antibiotics were used for experimental cultures, except when necessary for maintenance of the 3-

340 hydroxybutyrate production plasmid.

341

342 For the metabolome and proteome studies, cultures were grown in M9 medium (12.8 g.L $\mathrm{L}^{-1} \mathrm{Na}_{2} \mathrm{HPO}_{4} .7 \mathrm{H}_{2} \mathrm{O}, 3$

343 g.L $\mathrm{L}^{-1} \mathrm{KH}_{2} \mathrm{PO}_{4}, 0.5$ g.L $\mathrm{L}^{-1} \mathrm{NaCl}, 1$ g.L $\mathrm{L}^{-1} \mathrm{NH}_{4} \mathrm{Cl}$ and 0.24 g.L. $\mathrm{MgSO}_{4}$ ) supplemented with 4 g.L $\mathrm{L}^{-1}$ glucose, 2 g.L $\mathrm{L}^{-1}$

344 yeast extract and $1 \mathrm{ml} . \mathrm{L}^{-1}$ of a trace elements solution $\left(9.7 \mathrm{~g} . \mathrm{L}^{-1} \mathrm{FeCl}_{3}, 7.8\right.$ g.L ${ }^{-1} \mathrm{CaCl}_{2}, 0.218$ g.L $\mathrm{L}^{-1} \mathrm{CoCl}_{2} \cdot 6 \mathrm{H}_{2} \mathrm{O}$,

$345 \quad 0.156$ g.L $\mathrm{L}^{-1} \mathrm{CuSO}_{4} .5 \mathrm{H}_{2} \mathrm{O}, 0.118$ g.L ${ }^{-1} \mathrm{NiCl}_{3} \cdot 6 \mathrm{H}_{2} \mathrm{O}$ and 0.105 g.L ${ }^{-1} \mathrm{CrCl}_{3} \cdot 6 \mathrm{H}_{2} \mathrm{O}$ dissolved in $\left.0.1 \mathrm{M} \mathrm{HCl}\right)$. Seed

346 cultures $(300 \mathrm{~mL})$ were inoculated with $3 \mathrm{~mL}$ of $\mathrm{LB}$ starter culture in $1 \mathrm{~L}$ baffled Erlenmeyer flasks and grown

347 for $16 \mathrm{~h}$ overnight with shaking at $300 \mathrm{rpm}$.

348

349 Following inoculation of the fermentor (final volume of $3 \mathrm{~L}$ in a $10 \mathrm{~L}$ vessel), cultures were grown in batch

350 mode until the glucose supply was exhausted, indicated by a rise in dissolved oxygen (DO) and pH, and

351 confirmed by testing with a hand-held FreeStyle Optium glucose meter (Abbott Laboratories, UK). Feed

352 solution (180 g.L $\mathrm{L}^{-1}$ glucose, $22 \mathrm{~g} \mathrm{~L}^{-1} \mathrm{NH}_{4} \mathrm{Cl}, 5.42 \mathrm{~g} \cdot \mathrm{L}^{-1} \mathrm{MgSO}_{4}$ ) was then introduced at $1.5 \mathrm{~mL} \mathrm{~min}^{-1}$ by

353 peristaltic pump. Throughout the experiment, the temperature was controlled at $37^{\circ} \mathrm{C}$, agitation speed was a

354 constant $500 \mathrm{rpm}$ (sufficient to maintain DO above $40 \%$ ) and pH was maintained at 7.0 by addition of $5 \mathrm{M}$

$355 \mathrm{NaOH}$ as necessary. Control of foaming was only necessary for wild-type cultures without indole, and was

356 achieved by automatic addition of antifoam agent A (Sigma-Aldrich, US) controlled by a foam level probe.

357

358 After a 30 min equilibration period, indole dissolved in ethanol (1 M) was added in a single shot to a final

359 concentration of $3 \mathrm{mM}$. An equivalent volume of pure ethanol was added for no-indole controls. The growth of

360 each culture was monitored by measuring the optical density at $600 \mathrm{~nm}\left(\mathrm{OD}_{600}\right)$ of samples. W3110hns $\Delta 93$ 
361 cultures grew slower than the wild-type both before and after indole addition. Despite the different growth rates,

362 the $\mathrm{OD}_{600}$ at the start of the feeding stage was the same for all cultures.

363

364 For the production of 3-hydroxybutyrate (3HB), a similar strategy was followed to that described above.

365 However, a complex medium could be used as it was no longer necessary to avoid activating alternative

366 metabolic pathways, as in the metabolome study. This also allowed both strains to grow at equal rates. We used

367

368

369

370

371

372

373

374

375

376

377

378

379

380

381

382

383

384

385

386

387

388

389

390

terrific broth (TB) at all stages of the $3 \mathrm{HB}$ production experiments. TB medium consists of 24 g.L $\mathrm{L}^{-1}$ yeast extract, 12 g.L $\mathrm{L}^{-1}$ peptone, 9.4 g.L $\mathrm{L}^{-1} \mathrm{~K}_{2} \mathrm{HPO}_{4}, 2.2$ g.L $\mathrm{L}^{-1} \mathrm{KH}_{2} \mathrm{PO}_{4}, 4$ g.L $\mathrm{L}^{-1}$ glucose and 2.4 g.L $\mathrm{L}^{-1} \mathrm{MgSO}_{4}$. A $100 \mathrm{~mL}$ preculture of E. coli $\mathrm{W} 3110 h n s \Delta 93 / \mathrm{pTrctesB}$ haAB was grown overnight in $\mathrm{TB}$ medium at $37^{\circ} \mathrm{C}$ then used to inoculate the fermentor ( $5 \mathrm{~L}$ vessel), which contained a further $1.9 \mathrm{~L}$ of fresh TB medium. Ampicillin (100 $\mu \mathrm{g} / \mathrm{mL}$ ) was included in all growth media and the nutrient feed, to select for cells containing the plasmid.

When the original glucose supply was depleted (signaled by a rise in pH), a feed medium consisting of 190 g.L.-1 glucose, 108 g.L $\mathrm{L}^{-1}$ peptone, 84 g.L $\mathrm{L}^{-1}$ yeast extract, 9.4 g.L $\mathrm{L}^{-1} \mathrm{~K}_{2} \mathrm{HPO}_{4}, 2.2$ g.L $\mathrm{L}^{-1} \mathrm{KH}_{2} \mathrm{PO}_{4}$ and 1.2 g.L $\mathrm{MgSO}_{4}$ was pumped into the fermentor at an initial flow rate of $0.28 \mathrm{~mL} \cdot \mathrm{min}^{-1}$. The ratio of glucose to complex nitrogen in this feed was kept much higher than TB medium to provide a better stoichiometric balance. The flow rate was increased exponentially so as to double every $2 \mathrm{~h}$ pre-induction to keep pace with the growth rate of the cells. Indole was dissolved in ethanol to $150 \mathrm{mM}$ and pumped into the fermentor at a rate of $0.28 \mathrm{~mL} \cdot \mathrm{min}^{-1}$ for $2 \mathrm{~h}$, through a tube that exited below the level of the medium to ensure good dissolution. Induction was done with IPTG (1 mM final concentration) $30 \mathrm{~min}$ after the start of the indole feed. The feed rate post induction was kept constant since we observed a drop in the growth rate of the cells.

Cell growth was measured as $\mathrm{OD}_{600}$ following appropriate dilution and as cell dry weight (CDW) by collecting the cells from two $1 \mathrm{~mL}$ samples through centrifugation and drying in an oven until constant weight. The average of the two weights was reported. Glucose concentrations were recorded using a medical glucose meter and disposable enzyme assay strips. Substrate consumption rates (with respect to glucose) were calculated from a material balance on the amount fed per unit time and the residual glucose concentration in the culture medium. Following centrifugation at $17,000 \times \mathrm{g}$ for 2 minutes to remove the cells, samples of the supernatant $(1 \mathrm{~mL})$ were kept at $-80{ }^{\circ} \mathrm{C}$ before testing for $3 \mathrm{HB}$ concentrations using a $\beta$-hydroxybutyrate colorimetric assay kit (Cayman Chemicals, US). 
392 3-hydroxybutyrate production plasmid construction. Plasmid pTrctesBphaAB was constructed from plasmid $393 \quad \mathrm{pTrcphaCAB}_{\mathrm{Re}}$ which was generously provided by Dr. Takeharu Tsuge (Tokyo Institute of Technology, Japan)

394 (Kahar et al., 2005), by replacing the phaC gene with $\operatorname{tes} B$. The artificial operon thus created encoded for a 3-

395 enzyme pathway in which 3-hydroxybutyryl-CoA is produced from acetyl-CoA by PhaA and PhaB, and the

396 CoA moiety is then removed by TesB to leave 3-HB. The tesB gene was amplified by PCR from plasmid

397 pCA24N:TesB (Kitagawa et al., 2005) and the product was purified using a QIAQuick PCR purification column

398 (Qiagen, USA). Plasmid pTrcphaCAB ${ }_{\mathrm{Re}}$ was linearized by digestion with EcoRI and SalI and the plasmid

399 backbone was then ligated with the tesB fragment by Gibson Assembly according to the manufacturer's

400 instructions of a kit provided by New England Biolabs (US). The primers used for Gibson Assembly were:

401

402

403

Forward: AACAATTTCACACAGGAAACAGACCATGGAATTCAGATCTTTCG

404

405

Reverse: CAAAACAGCCAAGCTTGCATGCCTGCAGGTCGACTCTAGAGGAT

406

CCAAACCCGGTGAATTGGCGCA

407

408 Time-course study of metabolomics changes. Samples were taken immediately before indole addition and at

409 six other points over the next 4 hours $(5,15,30,60,120$ and $240 \mathrm{~min}$ after indole addition). Approximately 20

$410 \mathrm{~mL}$ samples were drawn aseptically from the fermentor, $1 \mathrm{~mL}$ aliquots of which were used for the metabolomics

411 study. The $\mathrm{OD}_{600}$ of each sample was measured with appropriate dilution and recorded, and later used to

412 normalize the metabolite concentrations. We obtained samples for metabolite quantification by vacuum filtering

$4131 \mathrm{~mL}$ of each culture and quenching the cells by immersion in cold $\left(-80^{\circ} \mathrm{C}\right)$ methanol within $30 \mathrm{sec}$ of

414 withdrawal. The samples were stored in methanol at $-80{ }^{\circ} \mathrm{C}$ until preparation for analysis.

415

416 LC-MS/MS analysis of metabolites. Prior to analysis, metabolites were extracted using a previously described

417 method with modifications (Soga, 2007; Yoshida et al., 2008). Briefly, the metabolites were extracted into a

$4181.2 \square \mathrm{ml}$ solvent mixture $\left(\mathrm{CHCl}_{3}: \mathrm{H}_{2} \mathrm{O}, 1: 1\right.$, v/v) containing $10 \square \mu \mathrm{g} . \mathrm{L}^{-1}$ of D-(+)-camphor-10-sulfonic acid as an

419 internal standard for semi-quantitative analysis. After centrifugation at $15,000 \times \square \mathrm{g}$ at $4{ }^{\circ} \mathrm{C}$ for $5 \square \mathrm{min}, 10 \mu \mathrm{L}$ of

420 the upper phase was used for quantification of intracellular metabolites by high-performance liquid 
421 chromatography coupled with electrospray ionization tandem mass spectrometry (LCMS-8040 triple quadrupole

422 LC-MS/MS spectrometer; Shimadzu, Japan) as described previously (Luo et al., 2007).

423

424 GC-MS analysis of metabolites. For GC-MS analysis, $70 \mu \mathrm{L}$ of the upper phase, as for LC-MS/MS analysis, 425 was transferred to a new tube and vacuum dried. The dried residue was derivatized for 90 min at $30{ }^{\circ} \mathrm{C}$ in 20 $426 \mathrm{mg} \cdot \mathrm{mL}^{-1}$ methoxyamine hydrochloride in pyridine $(20 \mu \mathrm{L})$. Subsequently, trimethylsilylation (TMS 427 derivatization) was performed for $30 \mathrm{~min}$ at $37^{\circ} \mathrm{C}$ and then for $2 \mathrm{~h}$ at room temperature with $\mathrm{N}$-methyl-N428 (trimethylsilyl)trifluoroacetamide (MSTFA, $50 \mu \mathrm{L}$ ) (Roessner et al., 2000; Strelkov et al., 2004). GC-MS was carried out using a GCMS-QP2010 Ultra (Shimadzu, Japan) equipped with a CP-Sil 8 CB-MS capillary column $430\left(30 \mathrm{~m} \times 0.25 \mathrm{~mm} \times 0.25 \mu \mathrm{m}\right.$; Agilent, USA). Helium was used as the carrier gas with a flow rate of $2.1 \mathrm{~mL}^{\mathrm{m}} \mathrm{min}{ }^{-}$

431 . The injection volume was $1 \mu \mathrm{L}$ with a split ratio of $1: 10$. An initial oven temperature of $60^{\circ} \mathrm{C}$ was maintained 432 for $10 \mathrm{~min}$, then raised to $315^{\circ} \mathrm{C}$ at $15^{\circ} \mathrm{C} \cdot \mathrm{min}^{-1}$, and maintained for $6 \mathrm{~min}$. The total running time was $33 \mathrm{~min}$. 433 The other settings were as follows: $250{ }^{\circ} \mathrm{C}$ interface temperature, $200{ }^{\circ} \mathrm{C}$ ion source temperature, and electron 434 impact (EI) ionization at $70 \mathrm{eV}$.

435

436 HPLC analysis for measurement of organic acids in medium. Supernatant of the cell broth, recovered after 437 centrifugation, was used for HPLC using a Prominence HPLC System (Shimadzu, Japan) with a conductivity 438 detector and two Shim-pack SCR-102H columns (300 mm x 8.0 mm; I.D., $7 \mu \mathrm{m}$; Shimadzu, Japan). The column 439 temperature was $48^{\circ} \mathrm{C}$ and the flow rate of the mobile phase ( $5 \mathrm{mM}$ p-toluenesulfonic acid; p-TSA) was 0.8 $440 \mathrm{~mL} \cdot \mathrm{min}^{-1}$. The flow rate of the $\mathrm{pH}$ buffering solution for the detector (5 mM p-TSA, $20 \mathrm{mM}$ Bis-Tris, and 0.1 441 mM EDTA-4H) was $0.5 \mathrm{~mL} \cdot \mathrm{min}^{-1}$.

442

443 2d-DIGE comparison of protein expression. The same $20 \mathrm{~mL}$ samples from the fermentation cultures as 444 described for the metabolomics study were used for the proteomic study. A $10 \mathrm{~mL}$ aliquot of each sample was 445 centrifuged at $4000 \times \mathrm{g}$ for 15 min to recover the cells. The pellet was then washed 3 times by repeated 446 suspension and centrifugation, in an ice-cold buffer consisting of $10 \mathrm{mM}$ Tris (pH 8.0) and $5 \mathrm{mM}$ magnesium 447 acetate. Washed pellets were stored at $-80{ }^{\circ} \mathrm{C}$ until all samples had been collected, and then prepared for analysis 448 simultaneously. 
450

451

452

453

454

455

456

457

458

459

460

461

462

463

464

465

466

467

468

469

470

471

472

473

474

475

476

477

478

479

Cells were resuspended in lysis buffer (7 M urea, $2 \mathrm{M}$ thiourea, $30 \mathrm{mM}$ Tris and 4\% (w/v) CHAPS) and lysed by sonication on ice. The sonication protocol consisted of 12 cycles of $10 \mathrm{sec}$ with $10 \mathrm{sec}$ rest periods between. The pulse amplitude was set to 15 Amp resulting in a pulse power of $8-9 \mathrm{~W}$. After complete lysis, the protein concentration was measured using a Bradford microplate assay procedure. Controls consisting of bovine serum albumin were prepared in the same lysis buffer to prepare a standard curve. The $\mathrm{pH}$ of each sample was also checked and found to be close to $\mathrm{pH} 8.5$, which is optimal for the labelling procedure.

An internal standard was created by pooling equal amounts of protein from every sample. For the test samples, $50 \mu \mathrm{g}$ of protein was labelled for each sample. Labelling was carried out with the CyDye DIGE Fluor minimal labelling kit (GE Healthcare, US) using $\mathrm{Cy} 2$ for the internal standard and $\mathrm{Cy} 3$ and $\mathrm{Cy} 5$ for test samples. Groups of two test samples were then combined together with an internal standard sample, and mixed with an equal volume of $2 \times$ sample buffer (7M urea, $2 \mathrm{M}$ thiourea, 2\% (w/v) CHAPS, $0.5 \%$ IPG buffer (pH $3-11 \mathrm{NL}$ ) and De-streak reagent). Finally, the volume was made up to $450 \mu \mathrm{L}$ with rehydration solution (7 M urea, $2 \mathrm{M}$ thiourea, $2 \%$ (w/v) CHAPS). Each sample was loaded onto a $24 \mathrm{~cm}$ Immobiline DryStrip (pH 3 - 11 NL) using the rehydration method, with rehydration proceeding for $12 \mathrm{~h}$ at $20^{\circ} \mathrm{C}$. Isoelectric focusing then proceeded with an initial step of $500 \mathrm{mV}$ for $1 \mathrm{~h}$, followed by a gradient to $100 \mathrm{mV}$ over $8 \mathrm{~h}$, a gradient to $8000 \mathrm{mV}$ over $3 \mathrm{~h}$ and a final step with the voltage held at $8000 \mathrm{mV}$ for $3.75 \mathrm{~h}$.

The second dimension electrophoresis was conducted using the Ettan DALT gel and electrophoresis system (GE Healthcare, USA). $24 \mathrm{~cm}$ pre-casted gels were used following equilibration of the focused IEF strips. 8 gels were run simultaneously with $12 \mathrm{~mA}$ per gel, with a recirculating pump and chiller to maintain the buffer temperature at $15{ }^{\circ} \mathrm{C}$, for $17 \mathrm{~h}$ until the bromophenol blue dye front just reached the end of the gel. The gels were then immediately scanned using a Typhoon 9400 variable mode imager (Amersham Biosciences, UK) and following the manufacturer's recommended settings. The images were analyzed to detect changes in protein concentrations using DeCyder 2-D v.6.5 image analysis software.

Protein digestion and identification. A preparatory gel containing $500 \mu \mathrm{g}$ of unlabeled, pooled samples was run under the same conditions as for the analytical gel, and post-stained using SYPRO Ruby (Fisher Scientific, Japan). Following spot matching in DeCyder 2-D, the selected spots were excised using an Ettan spot picker (Amersham Biosciences, UK). The spots were de-stained in $50 \mathrm{mM}$ ammonium bicarbonate containing $50 \%$ 
480

481

482

483

484

485

486

487

488

489

490

491

492

493

494

495

496

497

498

499

500

acetonitrile $(50 \mu \mathrm{L})$ for $10 \mathrm{~min}$ at $37^{\circ} \mathrm{C}$, dehydrated with acetonitrile $(25 \mu \mathrm{L})$ then dried in a vacuum centrifuge. To reduce cysteine residues, $100 \mathrm{mM}$ ammonium bicarbonate with $10 \mathrm{mM}$ dithiothreitol $(25 \mu \mathrm{L})$ was added for $15 \mathrm{~min}$ at $50{ }^{\circ} \mathrm{C}$, then $250 \mathrm{mM}$ iodoacetamide in $100 \mathrm{mM}$ ammonium bicarbonate $(2 \mu \mathrm{L})$ was then added and the spots were incubated for $15 \mathrm{~min}$ at room temperature in the dark for alkylation. After washing and dehydration as before, the protein in the dried gel debris was digested at $37^{\circ} \mathrm{C}$ overnight with $100 \mathrm{ng} / 10 \mu \mathrm{L}$ modified trypsin solution. The digested protein fragments were collected from the supernatant and extracted from the gel debris by the addition of $50-80 \%$ acetonitrile containing $1 \%$ trifluoroacetic acid $(3 \times 25 \mu \mathrm{L})$.

The resulting protein sample was resolved in $2 \%$ acetonitrile containing $0.1 \%$ trifluoroacetic acid and applied to the liquid chromatography (LC) system (Advance nanoLC; Bruker-Michrom, USA) coupled to an LTQ linear ion trap mass spectrometer (ThermoFisher, USA) with a nanospray ion source in positive mode. The peptides were separated on a NANO-HPLC C18 capillary column $(0.075 \mathrm{~mm}$ ID $\times 150 \mathrm{~mm}$ length, $3 \mathrm{~mm}$ particle size, Nikkyo Technos, Japan) using a linear gradient (25 $\mathrm{min}, 5-35 \%$ acetonitrile containing $0.1 \%$ formic acid) at a flow rate of $300 \mathrm{~nL} / \mathrm{min}$. The LTQ-MS was operated in top-3 data-dependent scan mode. The precursor ions were selected automatically for MS/MS analysis on the basis of their signal intensities. The parameters of LTQ were as follows: spray voltage, $2.3 \mathrm{kV}$; capillary temperature, $250^{\circ} \mathrm{C}$; mass range $(\mathrm{m} / \mathrm{z}), 400-1800$; collision energy, 35\%. Raw data was acquired by Xcalibur software. The MS/MS data were searched against the SwissProt 2014_10 database using MASCOT v.2.4.1 software (Matrix Science, UK). The MASCOT search parameters were as follows: enzyme, trypsin; fixed modifications, carbamidomethyl (Cys); variable modifications, oxidation (Met); peptide mass tolerance, $\pm 1.5 \mathrm{Da}$; fragment mass tolerance, $\pm 0.8 \mathrm{Da}$; max. missed cleavages, 1. Significant MASCOT scores were defined with $\mathrm{p} \leq 0.05$.

\section{Acknowledgments}

502 We would like to thank Dr Kenji Ohtawa (Riken Support Unit for Biomaterial Analysis, Japan) for technical 503 assistance with 2D-DIGE, Dr Masaya Usui (Riken Support Unit for Biomaterial Analysis, Japan) for technical 504 assistance with identification of protein spots, Dr Matthew Davey (Plant Sciences Department, University of 505 Cambridge, UK) for helpful discussions about data analysis and Dr Antonio De León Rodríguez (IPICYT, 506 Mexico) for critical reading of the manuscript. This project was funded by the Riken Foreign Postdoctoral 507 Researcher program.

\section{Competing interests}


510 Induction In Quiescence In Bacteria: Jan. 1, 2009) covering the Q-Cell system. The IP is owned by Cambridge

511 Enterprise (Cambridge University). D.K.S. stands to benefit from earnings arising from exploitation of Q-Cells

512 under the standard Cambridge University policy for income distribution. All other authors declare no financial or 513 commercial conflict of interest.

\section{References}

Balke, V.L., Gralla, J.D., 1987. Changes in the linking number of supercoiled DNA accompany growth transitions in Escherichia coli. J. Bacteriol. 169, 4499-4506.

Cabiscol, E., Tamarit, J., Ros, J., 2000. Oxidative stress in bacteria and protein damage by reactive oxygen species. Int. Microbiol. 3, 3-8. doi:10.2436/im.v3i1.9235

Cha, H.J., Srivastava, R., Vakharia, V.N., Rao, G., Bentley, W.E., 1999. Green fluorescent protein as a noninvasive stress probe in resting Escherichia coli cells. Appl. Environ. Microbiol. 65, 409-414.

Chen, C.-C., Walia, R., Mukherjee, K.J., Mahalik, S., Summers, D.K., 2015. Indole generates quiescent and metabolically active Escherichia coli cultures. Biotechnol. J. 10, 636-646.

Chen, X., Zhou, L., Tian, K., Kumar, A., Singh, S., Prior, B.A., Wang, Z., 2013. Metabolic engineering of Escherichia coli: A sustainable industrial platform for bio-based chemical production. Biotechnol. Adv. 31, 1200-1233.

Chimerel, C., Field, C.M., Piñero-Fernandez, S., Keyser, U.F., Summers, D.K., 2012. Indole prevents Escherichia coli cell division by modulating membrane potential. Biochim. Biophys. Acta 1818, 15901594. doi:10.1016/j.bbamem.2012.02.022

Chimerel, C., Murray, A., Oldewurtel, E.R., Summers, D.K., Keyser, U.F., 2013. The effect of bacterial signal indole on the electrical properties of lipid membranes. ChemPhysChem 14, 417-423.

Choi, J.H., Keum, K.C., Lee, S.Y., 2006. Production of recombinant proteins by high cell density culture of Escherichia coli. Chem. Eng. Sci. 61, 876-885. doi:10.1016/j.ces.2005.03.031

Cronan, Jr., J.E., Laporte, D., 2006. Tricarboxylic Acid Cycle and Glyoxylate Bypass. EcoSal Plus 1, 1-26. doi:10.1128/ecosalplus.3.5.2

Di Martino, P., Fursy, R., Bret, L., Sundararaju, B., Phillips, R.S., 2003. Indole can act as an extracellular signal to regulate biofilm formation of Escherichia coli and other indole-producing bacteria. Can. J. Microbiol. 49, 443-449. doi:10.1139/w03-056

Field, C.M., Summers, D.K., 2012. Indole inhibition of ColE1 replication contributes to stable plasmid maintenance. Plasmid 67, 88-94. doi:10.1016/j.plasmid.2011.11.004

Gaimster, H., Summers, D., 2015. Regulation of indole signalling during the transition of E. coli from exponential to stationary phase. PLoS One 10, e0136691. doi:10.1371/journal.pone.0136691

Ghazi, A., Therisod, H., Shechter, E., 1983. Comparison of lactose uptake in resting and energized Escherichia coli cells $\square$ : high rates of respiration inactivate the lac carrier. J. Bacteriol. 154, 92-103.

Hirakawa, H., Hayashi-Nishino, M., Yamaguchi, A., Nishino, K., 2010. Indole enhances acid resistance in Escherichia coli. Microb. Pathog. 49, 90-94. doi:10.1016/j.micpath.2010.05.002

Hirakawa, H., Inazumi, Y., Masaki, T., Hirata, T., Yamaguchi, A., 2005. Indole induces the expression of multidrug exporter genes in Escherichia coli. Mol. Microbiol. 55, 1113-1126. doi:10.1111/j.13652958.2004.04449.x

Hirakawa, H., Kodama, T., Takumi-Kobayashi, A., Honda, T., Yamaguchi, A., 2009. Secreted indole serves as a signal for expression of type III secretion system translocators in enterohaemorrhagic Escherichia coli O157:H7. Microbiology 155, 541-550. doi:10.1099/mic.0.020420-0 
Hommais, F., Krin, E., Laurent-Winter, C., Soutourina, O., Malpertuy, A., Le Caer, J., Danchin, A., Bertin, P., 2001. Large-scale monitoring of pleiotropic regulation of gene expression by the prokaryotic nucleoidassociated protein, H-NS. Mol. Microbiol. 40, 20-36.

Hoskisson, P. a., Hobbs, G., 2005. Continuous culture - Making a comeback? Microbiology 151, 3153-3159. doi:10.1099/mic.0.27924-0

Hsieh, L.S., Burger, R.M., Drlika, K., 1991. Bacterial DNA supercoiling and [ATP]/[ADP] changes associated with a transition to anaerobic growth. J. Mol. Biol. 219, 443-450.

Hua, Q., Yang, C., Oshima, T., Mori, H., Shimizu, K., 2004. Analysis of Gene Expression in Escherichia coli in Response to Changes of Growth-Limiting Nutrient in Chemostat Cultures. Society 70, 2354-2366. doi:10.1128/AEM.70.4.2354

Ishii, N., Nakahigashi, K., Baba, T., Robert, M., Soga, T., Kanai, A., Hirasawa, T., Naba, M., Hirai, K., Hoque, A., Ho, P.Y., Kakazu, Y., Sugawara, K., Igarashi, S., Harada, S., Masuda, T., Sugiyama, N., Togashi, T., Hasegawa, M., Takai, Y., Yugi, K., Arakawa, K., Iwata, N., Toya, Y., Nakayama, Y., Nishioka, T., Shimizu, K., Mori, H., Tomita, M., 2007. Multiple high-throughput analyses monitor the response of E. coli to perturbations. Science 316, 593-7. doi:10.1126/science.1132067

Kahar, P., Agus, J., Kikkawa, Y., Taguchi, K., Doi, Y., Tsuge, T., 2005. Effective production and kinetic characterization of ultra-high-molecular-weight poly [(R)-3-hydroxybutyrate] in recombinant Escherichia coli. Polym. Degrad. Stab. 87, 161-169.

Kitagawa, M., Ara, T., Arifuzzaman, M., Ioka-Nakamichi, T., Inamoto, E., Toyonaga, H., Mori, H., 2005. Complete set of ORF clones of Escherichia coli ASKA library (a complete set of E. coli K-12 ORF archive): unique resources for biological research. DNA Res. 12, 291-299.

Korshunov, S.S., Skulachev, V.P., Starkov, A.A., 1997. High protonic potential actuates a mechanism of production of reactive oxygen species in mitochondria. FEBS Lett. 416, 15-18. doi:10.1016/S00145793(97)01159-9

Krapp, A.R., Humbert, M.V., Carrillo, N., 2011. The soxRS response of Escherichia coli can be induced in the absence of oxidative stress and oxygen by modulation of NADPH content. Microbiology 157, 957-965. doi:10.1099/mic.0.039461-0

Lau, I.F., Filipe, S.R., Søballe, B., Økstad, O.-A., Barre, F.-X., Sherratt, D.J., 2004. Spatial and temporal organization of replicating Escherichia coli chromosomes. Mol. Microbiol. 49, 731-743. doi:10.1046/j.1365-2958.2003.03640.x

Laurent-Winter, C., Ngo, S., Danchin, A., Bertin, P., 1997. Role of Escherichia coli histone-like nucleoidstructuring protein in bacterial metabolism and stress response--identification of targets by twodimensional electrophoresis. Eur J Biochem 244, 767-773. doi:10.1111/j.1432-1033.1997.00767.x

Lee, H.H., Molla, M.N., Cantor, C.R., Collins, J.J., 2010. Bacterial charity work leads to population-wide resistance. Nature 467, 82-85. doi:10.1038/nature09354.Bacterial

Lee, J., Jayaraman, A., Wood, T.K., 2007. Indole is an inter-species biofilm signal mediated by SdiA. BMC Microbiol. 7. doi:10.1186/1471-2180-7-42

Lee, J.-H., Lee, J., 2010. Indole as an intercellular signal in microbial communities. FEMS Microbiol. Rev. 34, 426-444. doi:10.1111/j.1574-6976.2009.00204.x

Lee, S., 1996. High cell-density culture of Escherichia coli. Trends Biotechnol. 14, 98-105.

Li, Y., 2011. Recombinant production of antimicrobial peptides in Escherichia coli: A review. Protein Expr. Purif. 80, 260-267. doi:10.1016/j.pep.2011.08.001

Liu, Q., Ouyang, S.-P., Chung, A., Wu, Q., Chen, G.-Q., 2007. Microbial production of R-3-hydroxybutyric acid by recombinant E. coli harboring genes of phbA, phbB, and tesB. Appl. Microbiol. Biotechnol. 76, 811818. doi:10.1007/s00253-007-1063-0

Luo, B., Groenke, K., Takors, R., Wandrey, C., Oldiges, M., 2007. Simultaneous determinaton of multiple intracellular metabolites in glycolysis, pentose phosphate pathway and tricarboxylic acid cycle by liquid chromatography-mass spectrometry. J. Chromatogr. A 1147, 153-164.

Maharjan, R.P., Yu, P.L., Seeto, S., Ferenci, T., 2005. The role of isocitrate lyase and the glyoxylate cycle in Escherichia coli growing under glucose limitation. Res. Microbiol. 156, 178-183. doi:10.1016/j.resmic.2004.09.004

Maloy, S., Nunn, W., 1982. Genetic regulation of the glyoxylate shunt in Escherichia coli K-12. J. Bacteriol. 
149, 173-180.

Meier, S., Jensen, P.R., Duus, J.O., 2011. Real-time detection of central carbon metabolism in living Escherichia coli and its response to perturbations. FEBS Lett. 585, 3133-3138. doi:10.1016/j.febslet.2011.08.049

Mukherjee, K.J., Rowe, D.C.D., Watkins, N.A., Summers, D.K., 2004. Studies of single-chain antibody expression in quiescent Escherichia coli. Appl. Environ. Microbiol. 70, 3005-3012.

Murphy, C.D., 2012. The microbial cell factory. Org. Biomol. Chem. 10, 1949. doi:10.1039/c2ob06903b

Nikaido, E., Giraud, E., Baucheron, S., Yamasaki, S., Wiedemann, A., Okamoto, K., Takagi, T., Yamaguchi, A., Cloeckaert, A., Nishino, K., 2012. Effects of indole on drug resistance and virulence of Salmonella enterica serovar Typhimurium revealed by genome-wide analyses. Gut Pathog. 4, 5. doi:10.1186/17574749-4-5

Ohniwa, R.L., Morikawa, K., Kim, J., Ohta, T., Ishihama, A., Wada, C., Takeyasu, K., 2006. Dynamic state of DNA topology is essential for genome condensation in bacteria. EMBO J. 25, 5591-602. doi:10.1038/sj.emboj.7601414

Ornston, L., Ornston, M., 1969. Regulation of glyoxylate metabolism in Escherichia coli K-12. J. Bacteriol. 98, 1098-1108.

Patrick, W.M., Quandt, E.M., Swartzlander, D.B., Matsumura, I., 2007. Multicopy suppression underpins metabolic evolvability. Mol. Biol. Evol. 24, 2716-2722. doi:10.1093/molbev/msm204

Roessner, U., Wagner, C., Kopka, J., Trethewey, R., Willmitzer, L., 2000. Simultaneous analysis of metabolites in potato tuber by gas chromatography-mass spectrometry. Plant J. 23, 131-142.

Rowe, D.C.D., Summers, D.K., 1999. The quiescent-cell expression system for protein synthesis in Escherichia coli. Appl. Environ. Microbiol. 65, 2710-2715.

Singh, A.B., Sharma, A.K., Mukherjee, K.J., 2012. Analyzing the metabolic stress response of recombinant Escherichia coli cultures expressing human interferon-beta in high cell density fed batch cultures using time course transcriptomic data. Mol. Biosyst. 8, 615-628. doi:10.1039/c1mb05414g

Sobetzko, P., Travers, A., Muskhelishvili, G., 2012. Gene order and chromosome dynamics coordinate spatiotemporal gene expression during the bacterial growth cycle. Proc. Natl. Acad. Sci. U. S. A. 109, E42-50. doi:10.1073/pnas.1108229109

Soga, T., 2007. Capillary electrophoresis-mass spectrometry for metabolomics. Methods Mol. Biol. 358, 129137.

Strelkov, S., Elstermann, M. von, Schomburg, D., 2004. Comprehensive analysis of metabolites in Corynebacterium glutamicum by gas chromatography/mass spectrometry. Biol. Chem. 385, 853-861.

Tai, Y.C., Speed, T.P., 2006. A multivariate empirical Bayes statistic for replicated microarray time course data. Ann. Stat. 34, 2387-2412. doi:10.1214/009053606000000759

Tartof, K., Hobbs, C., 1987. Improved media for growing plasmid and cosmid clones. Focus Life Technol. 9, 10. doi:10.1186/1475-2859-9-11

Tseng, H.-C., Martin, C.H., Nielsen, D.R., Prather, K.L.J., 2009. Metabolic engineering of Escherichia coli for enhanced production of (R)- and (S)-3-hydroxybutyrate. Appl. Environ. Microbiol. 75, 3137-45. doi:10.1128/AEM.02667-08

Van Bodegom, P., 2007. Microbial maintenance: A critical review on its quantification. Microb. Ecol. 53, 513523. doi:10.1007/s00248-006-9049-5

Vega, N.M., Allison, K.R., Samuels, A.N., Klempner, M.S., Collins, J.J., 2013. Salmonella typhimurium intercepts Escherichia coli signaling to enhance antibiotic tolerance. Proc. Natl. Acad. Sci. U.S.A. 110, 14420-25.

Wang, D., Ding, X., Rather, P.N., 2001. Indole can act as an extracellular signal in Escherichia coli. J. Bacteriol. $183,4210-4216$.

Wood, T.K., 2009. Insights on Escherichia coli biofilm formation and inhibition from whole-transcriptome profiling. Environ. Microbiol. 11, 1-15. doi:10.1111/j.1462-2920.2008.01768.x

Yoshida, S., Imoto, J., Minato, T., Oouchi, R., Sugihara, M., Imai, T., 2008. Development of bottom-fermenting Saccharomyces strains that produce high SO2 levels, using integrated metabolome and transcriptome analysis. Appl. Environ. Microbiol. 74, 2787-2796.

Yu, C., Cao, Y., Zou, H., Xian, M., 2011. Metabolic engineering of Escherichia coli for biotechnological 
bioRxiv preprint doi: https://doi.org/10.1101/082305; this version posted October 20, 2016. The copyright holder for this preprint (which was not certified by peer review) is the author/funder. All rights reserved. No reuse allowed without permission.

production of high-value organic acids and alcohols. Appl. Microbiol. Biotechnol. 89, 573-583. doi:10.1007/s00253-010-2970-z 